\title{
A Case of Repetitive Consciousness Disturbance with Hypercapnia due to Nonconvulsive Status Epilepticus in Klippel-Feil Syndrome
}

\author{
Hiroki Nagasawa, MD, Taishi Dotare, MD, Ikuto Takeuchi, MD, Kei Jitsuiki, MD, Shunsuke Madokoro, \\ MD, Norihito Takahashi, MD, Hiromichi Ohsaka, MD, PhD, Kouhei Ishikawa, MD, Kazuhiko Omori, MD, \\ PhD and Youichi Yanagawa, MD, PhD*
}

Department of Acute Critical Care Medicine, Shizuoka Hospital, Juntendo University, Japan

\begin{abstract}
A 59-year-old female complained palpitation in the morning. She was found in unconsciousness by her family and transported to our department. Her past history was she had torticollis, unilateral renal agenesis and dextrocardia since her birth. She had limited range of motion of bilateral brachiums and left hand dysesthesia due to torticollis since over 50-years-old. On arrival, she was in coma state with severe hypoxia and hypercapnia. Initially, she underwent diagnosis of status epileptic and/or over dose inducing coma, acute lung failure and liver dysfunction. Her consciousness, respiratory and liver function gradually improved. However, she temporally became unconsciousness and hypercapnia so that ceasing of mechanical ventilation resulted in failure and she received tracheostomy. She had abnormal eye or oral moving, when she became unconsciousness and hypercapnia attack. However, three times of electroencephalogram did not show epileptic wave. As every trial of ceasing mechanical ventilation resulted in failure so that the patient received infusion of butanamide even neurologist did not recommend. After this trial, she had never become unconsciousness and hypercapnia. This is the first case of nonconvulsive status epilepticus in a patient with Klippel-Feil syndrome. Physicians should suspect nonconvulsive status epilepticus when the patient had consciousness disturbance even an electroencephalogram is normal.
\end{abstract}

\section{Keywords}

Nonconvulsive status epilepticus, Klippel-Feil syndrome, Anticonvulsant

\section{Introduction}

Klippel-Feil syndrome presents with an abnormal fusion of 2 or more bones in the cervical spine. This creates a characteristic appearance of a short neck with resulting facial asymmetry, low hairline, and limited neck mobility. This syndrome often complicates cardiac, gastrointestinal, and urinary disorders [1-4]. We here in report a case of repetitive consciousness disturbance with hypercapnia due to nonconvulsive status epilepticus in Klippel-Feil Syndrome.

\section{Case Presentation}

A 59-year-old female complained palpitation in the morning. She was found in unconsciousness by her family and transported to our department. Her past history was she had torticollis, unilateral renal agenesis and dextrocardia since her birth. She received appendectomy at 10 -years-old. She had hypertension and dyslipidemia since she was 40-years-old. She had limited range of motion of bilateral brachiums and left hand dysesthesia due to torticollis since over 50-yearsold. She had also bilateral non functioning adrenal hyperpla- sia. She felt palpitation in a few weeks. She had prescription of Linagliptin, Olmesartan, Rosuvastatin, Famotidine, Lorazepam, Paroxetine, Metformin, Glimepiride, Sertraline, magnesium and KCL. Her family history was no remarkable. On arrival, her Glasgow Coma Scale was E1V1M1. Her blood pressure was $189 / 88 \mathrm{mmHg}$, heart rate was 80 beats per minute, percutaneous saturation was $71 \%$ under $10 \mathrm{~L}$ per minute of oxygen and body temperature was 37.4 Celsius. She had moist rare on auscultation. Electrocardiogram and cardiac

*Corresponding author: Youichi Yanagawa, Department of Acute Critical Care Medicine, Shizuoka Hospital, Juntendo University, 1129 Nagaoka, Izunokuni City, Shizuoka, 410-2295, Japan, Tel: 055-948-3111

Accepted: June 10, 2019

Published online: June 12, 2019

Citation: Nagasawa H, Dotare T, Takeuchi I, et al. (2019) A Case of Repetitive Consciousness Disturbance with Hypercapnia due to Nonconvulsive Status Epilepticus in Klippel-Feil Syndrome. Sch J Emerg Med Crit Care 3(1):67-70 
Citation: Nagasawa H, Dotare T, Takeuchi I, et al. (2019) A Case of Repetitive Consciousness Disturbance with Hypercapnia due to Nonconvulsive Status Epilepticus in Klippel-Feil Syndrome. Sch J Emerg Med Crit Care 3(1):67-70

sonography findings were negative. The results of an arterial blood gas analysis were $\mathrm{pH}$ of $7.071, \mathrm{PCO}_{2} 110 \mathrm{mmHg}, \mathrm{PO}_{2}$ $47.0 \mathrm{mmHg}, \mathrm{HCO}_{3}^{-} 30.4 \mathrm{mmol} / \mathrm{l}$, base excess $-3.7 \mathrm{mmol} / \mathrm{l}$ and

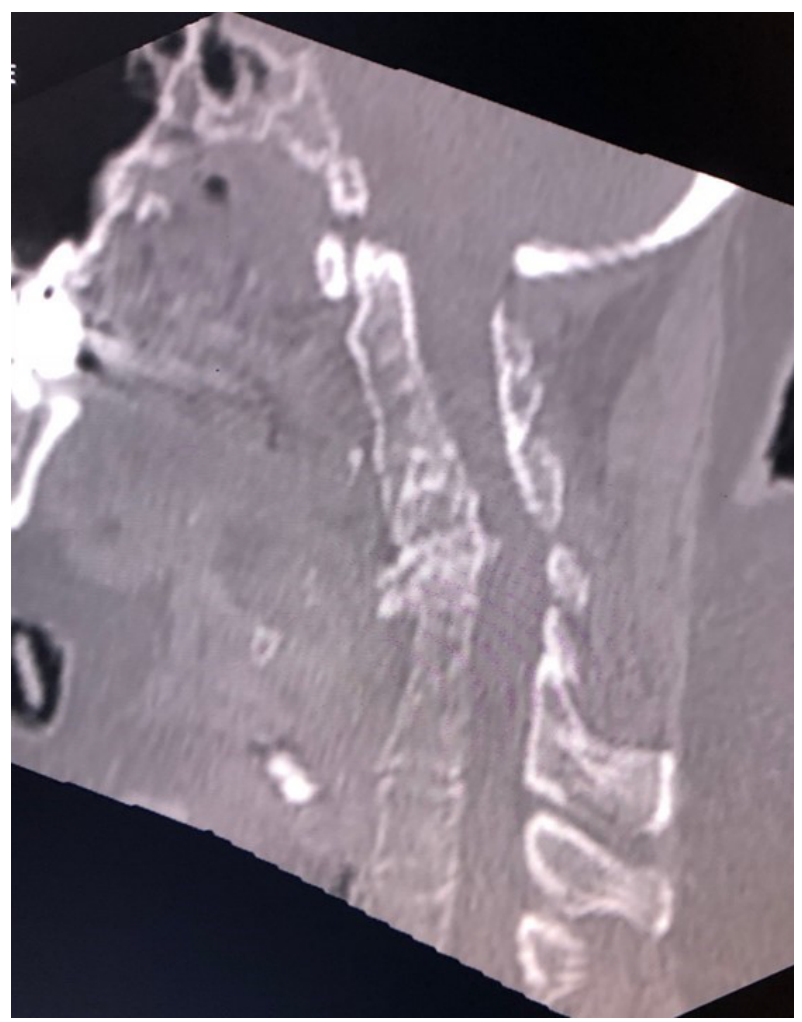

Figure 1: Cervical sagittal view of computed tomography. The CT depicted fusion of cervical bones. lactate $7.5 \mathrm{mmol} / \mathrm{l}$ under $10 \mathrm{~L}$ of oxygen via reservoir face mask. Chest roentgen showed dextrocardia with hypertrophy and decreased bilateral lung fields. As she had acute respiratory distress and convulsion at emergency room so that she underwent emergency tracheal intubation with mechanical ventilation. Head computed tomography (CT) was negative and truncal CT depicted fusion of cervical bones, scoliosis, dextrocardia, bilateral atelectasis due to aspiration, bilateral adrenal hypertrophy, left kidney agenesis, abdominal wall herniation and malingestion of ring in abdomen (Figure 1 and Figure 2). Head magnetic resonance image showed fluid collection in right maxillary sinus but no new ischemic lesion in brain. The results of a blood and cerebral spinal fluid analysis were shown in Table 1. Initially, she underwent diagnosis of status epileptic and/or overdose inducing coma, acute lung failure due to aspiration pneumonia and atelectasis, and liver dysfunction. After MRI, she made extubation for herself, however, her respiratory function deteriorated soon so that she underwent tracheal intubation again. As she had laryngeal edema and acute respiratory distress syndrome so that she received tracheostomy on the $2^{\text {nd }}$ hospital day. Her consciousness, respiratory and liver function gradually improved. She could obey order in $11^{\text {th }}$ hospital day so that she underwent continuous positive airway pressure mode. However, she temporally became unconsciousness and hypercapnia during spontaneous respiration every within a few days so that ceasing of mechanical ventilation resulted in failure. She received tracheostomy for difficulty of ceasing mechanical ventilation. As she had abnormal eye or oral moving when she became unconsciousness and hypercapnia, she had suspicious of nonconvulsive status epilepticus. However, three times of electroencephalogram did not show epileptic wave so that

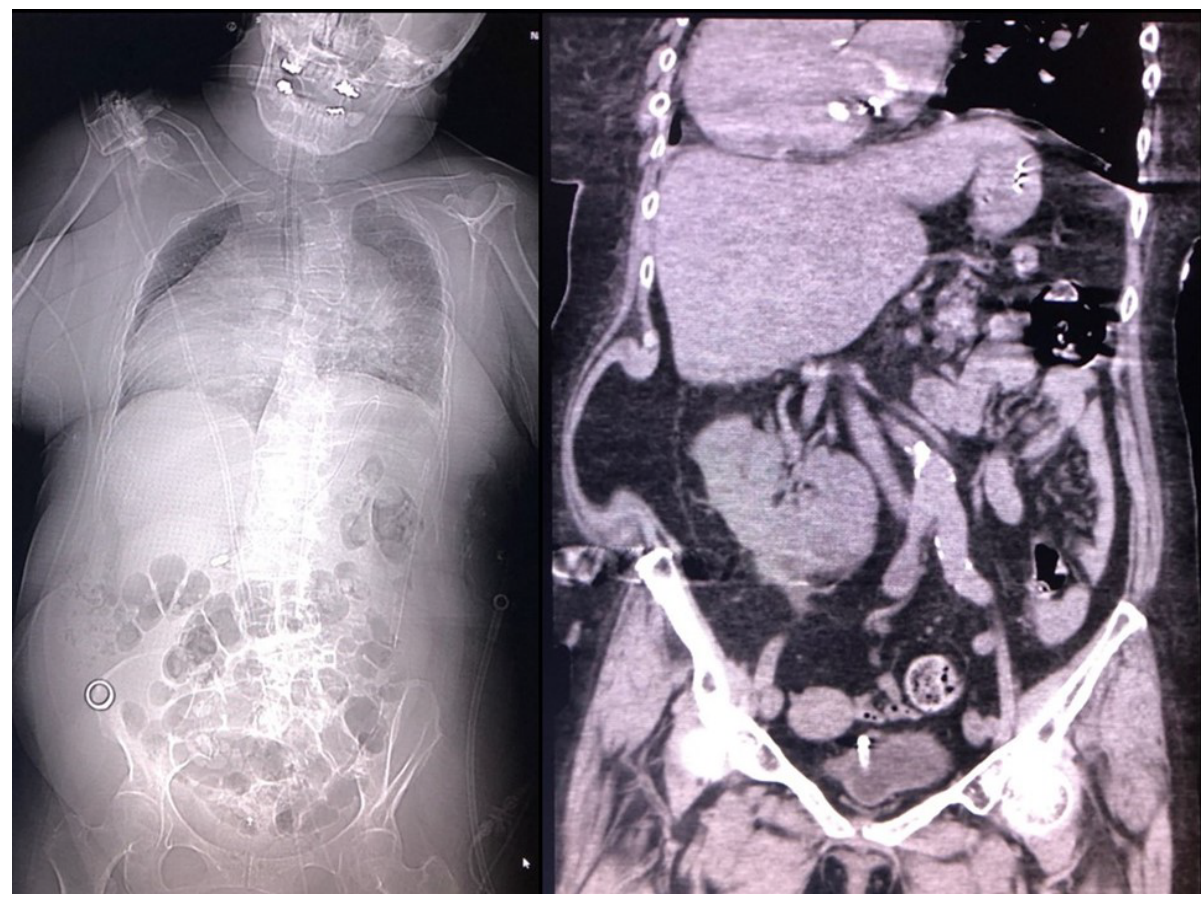

Figure 2: Truncal computed tomography (left, scout view; right, coronal view).

The CT depicted scoliosis, dextrocardia, bilateral atelectasis due to aspiration, bilateral adrenal hypertrophy, left kidney agenesis, abdominal wall herniation and malingestion of ring in abdomen. 
Citation: Nagasawa H, Dotare T, Takeuchi I, et al. (2019) A Case of Repetitive Consciousness Disturbance with Hypercapnia due to Nonconvulsive Status Epilepticus in Klippel-Feil Syndrome. Sch J Emerg Med Crit Care 3(1):67-70

Table 1: The laboratory analysis results.

\begin{tabular}{|c|c|}
\hline \multicolumn{2}{|l|}{ Cell blood count } \\
\hline White blood count & $9700 / \mu l$ \\
\hline Hemoglobin & $13.7 \mathrm{~g} / \mathrm{dl}$ \\
\hline Platelet & $22.8 \times 10^{4} / \mu \mathrm{l}$ \\
\hline \multicolumn{2}{|l|}{ Serum biochemical data } \\
\hline Total protein & $7.0 \mathrm{~g} / \mathrm{dl}$ \\
\hline Aspartate aminotransferase & $1613 \mathrm{IU} / \mathrm{I}$ \\
\hline v-glutamyl transpeptidase & $149 \mathrm{IU} / \mathrm{L}$ \\
\hline Creatine phosphokinase & $234 \mathrm{IU} / \mathrm{I}$ \\
\hline Blood urea nitrogen & $39.4 \mathrm{mg} / \mathrm{dl}$ \\
\hline Creatinine & $0.92 \mathrm{mg} / \mathrm{dl}$ \\
\hline Potassium & $4.1 \mathrm{mEq} / \mathrm{l}$ \\
\hline Albumin & $4.4 \mathrm{~g} / \mathrm{dl}$ \\
\hline Alanine aminotransferase & $1671 \mathrm{U} / \mathrm{I}$ \\
\hline Alkaline Phosphatase & $377 \mathrm{IU} / \mathrm{L}$ \\
\hline Total bilirubin & $1.0 \mathrm{mg} / \mathrm{dl}$ \\
\hline Glucose & $219 \mathrm{mg} / \mathrm{dl}$ \\
\hline Sodium & $149 \mathrm{mEq} / \mathrm{l}$ \\
\hline \multicolumn{2}{|l|}{ Coagulation } \\
\hline Activated partial thromboplastin time & $26.7(27.4) \mathrm{sec}$ \\
\hline Prothrombin time & $15.7(12.1) \mathrm{sec}$ \\
\hline Fibrinogen & $225 \mathrm{mg} / \mathrm{dl}$ \\
\hline Fibrinogen degradation products & $36.4 \mu \mathrm{g} / \mathrm{mL}$ \\
\hline \multicolumn{2}{|l|}{ Cerebral spinal fluid } \\
\hline Cell count & $1 / \mathrm{mm}^{3}$ \\
\hline Glucose & $133 \mathrm{mg} / \mathrm{dl}$ \\
\hline Protein & $36 \mathrm{mg} / \mathrm{dl}$ \\
\hline
\end{tabular}

neurologists did not recommend infusion of anticonvulsant. As every trial of ceasing mechanical ventilation resulted in failure so that we decided to infusion of butanamide for the patient on the $43^{\text {rd }}$ hospital day. After this trial, she had never become unconsciousness and hypercapnia so that she could breathe for herself without mechanical ventilation assist. In two weeks from commencement of butanamide, tracheal tube was successfully removed. After she could speak, we noticed the patient had disturbance of hearing due to serous otitis media and deterioration of her upper extremities movements. Follow up MRI incidentally revealed fluid collection in bilateral mastoid air cells in addition to right maxillary sinus probably due to prolonged intensive care (Figure 3) [5]. As she denied overdose, we finally diagnosed that her initial consciousness disturbance was due to statues epilepsy with aspiration pneumonia and hypoxic liver dysfunction, following nonconvulsive status epilepticus [6,7]. Deterioration of her upper extremities movements may be based on abnormal neck movement by status epilepsy or critical illness polyneuropathy and myopathy. As she had difficulty movement of bilateral brachium, she was transferred to another medical facility for rehabilitation.

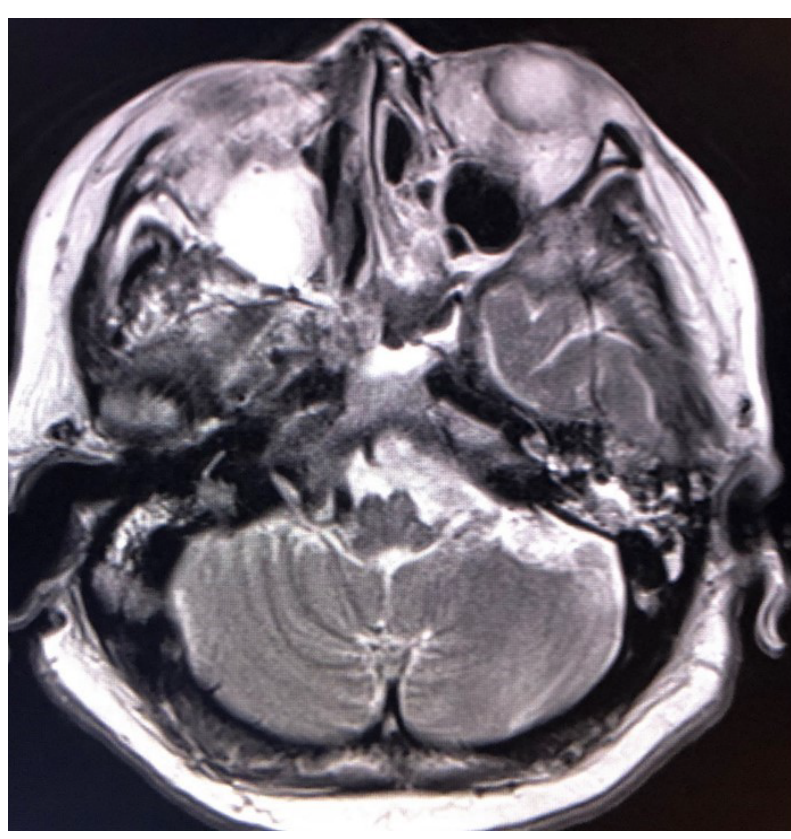

Figure 3: Follow up magnetic resonance image.

The MRI showed bilateral fluid collection in mastoid air cells which had not been found on MRI on arrival.

\section{Discussion}

This is the first case of nonconvulsive status epilepticus in a patient with Klippel-Feil syndrome. There is only one report which narrated complication of convulsion in a patient with Klippel-Feil syndrome [8]. Detail of epilepsy was not investigated due to Turkish report. This case did not complicate Chiari malformation or basilar impression which may induce convulsion. Etiology of epilepsy may be induced by brain abnormality based on genetic disturbance or aging or side effect of multiple drugs that the patient had [9-12].

The present case did not show epileptic wave as far as on the electroencephalogram. However, normal electroencephalogram could not deny epilepsy because approximate $10 \%$ patients did not show epileptic was on the electroencephalogram [13]. Accordingly, clinical diagnosis for epilepsy should be executed based on clinical findings. The electroencephalogram was one of assistant methods to diagnose epilepsy. As present case did not have unconsciousness and hypercapnia attack after butanamide treatment, this attack was diagnosed as nonconvulsive status epilepticus even the electroencephalogram was normal.

\section{Conclusion}

This is the first case of nonconvulsive status epilepticus in a patient with Klippel-Feil syndrome. Physicians should suspect nonconvulsive status epilepticus when the patient had consciousness disturbance even an electroencephalogram is normal.

\section{Conflict of Interest Statement}

The authors declare no conflicts of interest in association with this study. 
Citation: Nagasawa H, Dotare T, Takeuchi I, et al. (2019) A Case of Repetitive Consciousness Disturbance with Hypercapnia due to Nonconvulsive Status Epilepticus in Klippel-Feil Syndrome. Sch J Emerg Med Crit Care 3(1):67-70

\section{Acknowledgements}

This manuscript received funding from the Ministry of Education, Culture, Sports, Science and Technology-Supported Program for the Strategic Research Foundation at Private Universities, 2015-2019. The constitution of total researching system for comprehensive disaster medical management, corresponding to wide-scale disaster.

\section{References}

1. Menger RP, Notarianni C (2018) Klippel Feil Syndrome. StatPearls.

2. McBride WZ (1992) Klippel-Feil syndrome. Am Fam Physician 45: 633-635.

3. Futane S, Salunke P (2013) Klippel-Feil syndrome with atlantoaxial dislocation, anomalous vertebral artery, dextrocardia and situs inversus. Clin Neurol Neurosurg 115: 2304-2306.

4. Kumar D, Karoli R, Fatima J, et al. (2012) Klippel-Feil syndrome with unilateral renal agenesis and renal failure. J Assoc Physicians India 60: 68-69.

5. Decell MK, Gordon JB, Silver K, et al. (1994) Fulminant hepatic failure associated with status epilepticus in children: Three cases and a review of potential mechanisms. Intensive Care Med 20: 375-378.
6. Huyett $P$, Raz $Y$, Hirsch BE, et al. (2017) Radiographic mastoid and middle ear effusions in intensive care unit subjects. Respir Care 62: 350-356.

7. Kaplan PW (1996) Nonconvulsive status epilepticus in the emergency room. Epilepsia 37: 643-650.

8. Mahiroğullari M, Ozkan H, Yildirim N, et al. (2006) Klippel-Feil syndrome and associated congenital abnormalities: Evaluation of 23 cases. Acta Orthop Traumatol Turc 40: 234-239.

9. Yajnik VH, Hinduja AK, Vyas DK, et al. (1972) Myoclonus epilepsy associated with basilar impression. J Assoc Physicians India 20: 325-328.

10. Granata T, Valentini LG (2011) Epilepsy in type 1 Chiari malformation. Neurol Sci 32: S303-S306.

11. Kang BS, Jhang Y, Kim YS, et al. (2014) Etiology and prognosis of non-convulsive status epilepticus. J Clin Neurosci 21: 1915-1919.

12. Taniguchi G, Miyajima M, Watanabe M, et al. (2014) Nonconvulsive status epilepticus in the elderly associated with newer antidepressants used at therapeutic doses: A report of three cases. Epilepsy Behav Case Rep 3: 8-11.

13. Smith S (2005) EEG in the diagnosis, classification, and management of patients with epilepsy. I Neurol Neurosurg Psychiatry 76: 2-7. 